\title{
Evaluation of effective use of dredged soil as containment dikes of a disposal pond in Japan
}

Katsuhide Nishizono MS

Director, Planning Division, Coastal Development Institute of Technology,

Tokyo, Japan (Orcid:0000-0003-4779-2407) (corresponding author: nishizono_k89tu@icloud.com)

Yasuhiro Sega MS

Director, Kitakyushu Port and Airport Office, Ministry of Land,

Infrastructure, Transport and Tourism, Kitakyushu City, Japan
Masaaki Katagiri PhD

Chief Civil Engineer, Nikken Sekkei Civil Engineering, Tokyo, Japan

Yoichi Watabe PhD

Professor, Hokkaido University, Sapporo City, Japan (Orcid:0000-00021841-5816)

An extra fill on a revetment was constructed by using mechanically dewatered clay (MDC) made from dredged material in the third area of the Shinmoji-Oki disposal pond (S-3), Japan, in 2011. Since MDC is an artificial material, its long-term stability has not been confirmed. To understand the long-term stability of the constructed revetment, mechanical tests, such as box shear tests, were conducted on block samples taken from two designated areas of the extra fill on the revetment over the 10 years since its construction (2011-2020). As a result, it was confirmed that the shear strength under certain overburden effective stress sufficiently satisfied the value assumed at the designing stage and the strength properties did not change much after 10 years, although the strength constants varied.

Keywords: disposal pond/dredged clay/effective use/mechanical dewatering

\author{
Notation \\ $C_{\mathrm{cd}} \quad$ apparent cohesion under consolidated undrained \\ condition \\ $c_{\mathrm{d}} \quad$ failure criterion \\ $D_{10}, D_{60}$ diameters at the percentage passing by masses of 10 \\ and $60 \%$, respectively \\ $f_{\mathrm{s}} \quad$ sleeve friction \\ $q_{\mathrm{t}} \quad$ tip resistance \\ $S_{\mathrm{r}} \quad$ degree of saturation \\ $s_{\mathrm{u}} \quad$ shear strength \\ $U_{\mathrm{c}} \quad$ uniformity coefficient \\ $v_{\mathrm{s}} \quad$ surface wave velocity \\ $w \quad$ water content \\ $w_{\mathrm{L}} \quad$ liquid limit \\ $\rho_{\mathrm{d}} \quad$ dry density \\ $\rho_{\mathrm{m}} \quad$ moisture density \\ $\rho_{\mathrm{t}} \quad$ wet density \\ $\sigma \quad$ normal stress \\ $\tau \quad$ shear strength \\ $\phi_{\mathrm{cd}} \quad$ angle of shear resistance under consolidated \\ undrained condition \\ $\phi_{\mathrm{d}}$
}

\section{Introduction}

Dredging of sea-bottom sediment in harbours has long been performed for maintaining the required depth of navigation channels, and this will continue in the future. For the protection of the marine environment, dredged materials (mostly clay) have been and will continue to be discharged into a pond surrounded by revetments in the sea. The pump-dredged clay in the Kanmon waterway, off Kyushu Island in Japan, is discharged into the Shinmoji-Oki disposal pond. There are three areas in this pond, and two areas have already been filled with the pump-dredged clay. Currently, the clay is

discharged into the third area (S-3) (see Figure 1), but the acceptable capacity is limited. Therefore, it is necessary to utilise the current disposal pond in some ways until a new one becomes operational. There are three available measures: $(a)$ increasing the capacity of the existing disposal pond by constructing an extra fill on the revetment, (b) reuse of dredged clay as a material for the revetment and (c) volume reduction of the already accumulated clay deposit in the pond. In this project, it was decided to adopt measures $(a)$ and $(b)$. In other words, the dredged clay is mechanically dewatered and reused as a material for extra fill on revetments.

The S-3 area is $482 \mathrm{~m}$ by $1485 \mathrm{~m}$ and is surrounded by revetments. Initially, the revetment height was Datum Line (DL) + $8.0 \mathrm{~m}$, and the pond capacity was $12000000 \mathrm{~m}^{3}$ (see Figure 2). To increase its capacity, the revetment was raised using mechanically dewatered clay (MDC) lumps made by forcing out pore water from the dredged clay (Murayama et al., 2004). The height of the revetment with extra fill is DL $+12.0 \mathrm{~m}$, and the capacity has been expanded by approximately $3100000 \mathrm{~m}^{3}$ (see Figure 3). Additionally, the volume of MDC lumps used for the extra fill on revetments was approximately $940000 \mathrm{~m}^{3}$. In other words, it was possible to increase the volume available for discharge into the pond by approximately 4 million $\mathrm{m}^{3}$ (Katagiri and Terashi, 2005).

While mountain soil is typically used as the material for revetments, MDC lumps were used for the first time in Japan in the S-3 area. The stability of the revetment at the design stage using MDC lumps was evaluated by circular slip failure analysis in which physical and strength parameters such as the unit weight of MDC lumps, $C_{\mathrm{cd}}$ and $\phi_{\mathrm{cd}}$ are obtained by conducting various laboratory experiments and field experiments. The physical characteristics of MDC lumps were those obtained immediately 
Evaluation of effective use of dredged soil as containment dikes of a disposal pond in Japan

Nishizono, Sega, Katagiri and Watabe

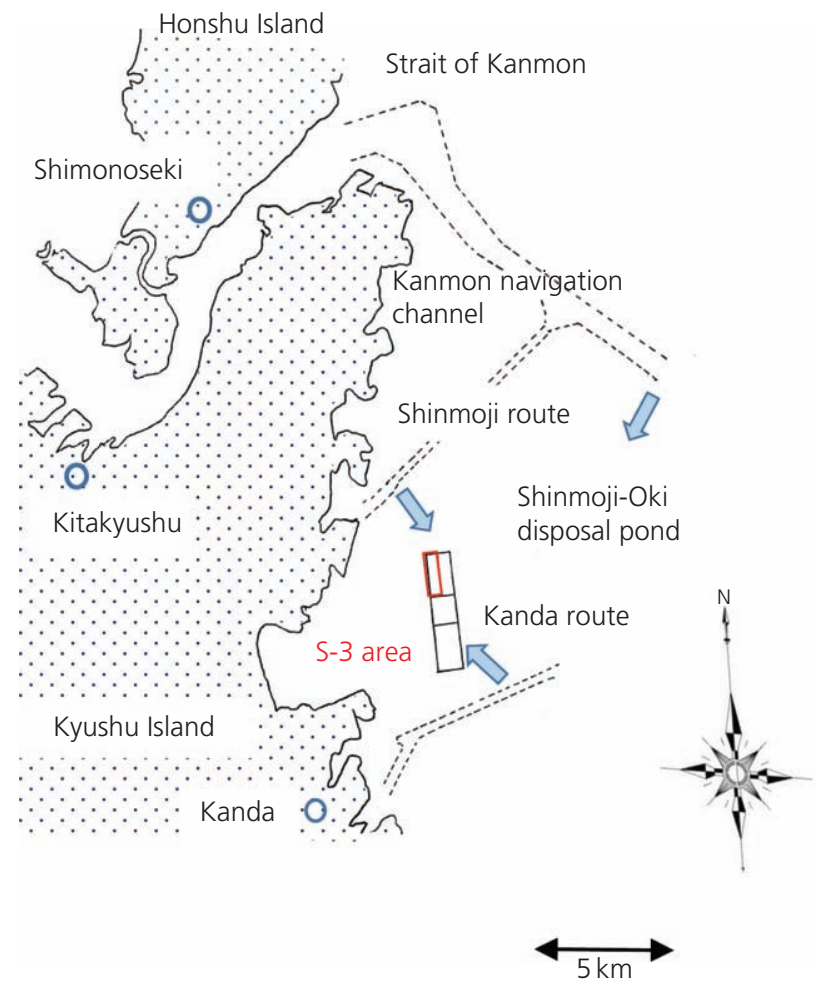

Figure 1. Location of the Shinmoji-Oki disposal pond

after production. However, since MDC lumps are artificial materials, MDC's long-term characteristics have not been studied. Therefore, in this paper, the authors will evaluate the stability of MDC lumps by assessing the changes over time in MDC's mechanical properties from 2011, when the extra fill was placed to raise the revetment, to the present (Nakamichi et al., 2008).

\section{Characteristics of MDC lumps used for extra fill on revetments}

\section{MDC lump production process}

The dewatered soil was prepared by using the high-pressure filter press method, which is classified as a pressurised dewatering and

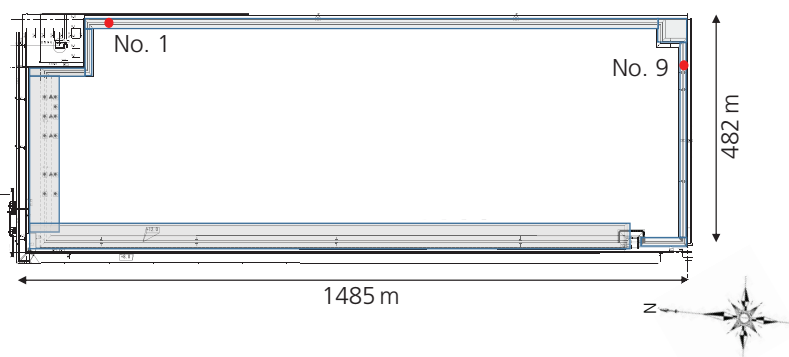

Figure 2. S-3 area of the Shinmoji-Oki disposal pond

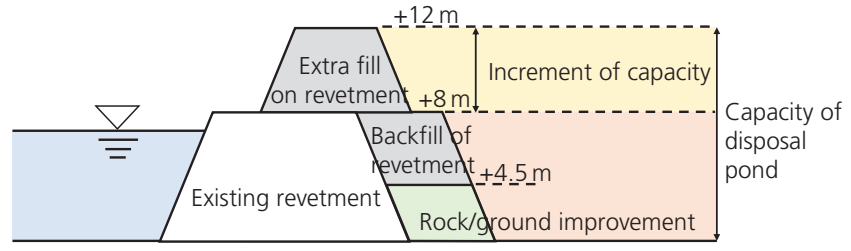

Figure 3. Concept of the capacity increment method using MDC lumps

filtration method. Specifically, the clay slurry is fed at high pressure into a filter chamber surrounded by a filter cloth, where it is filtered and dewatered. This principle is the same as that of osmotic consolidation, where the pore water flow imposes an effective stress on the clay particles, which in turn consolidates the clay sample in the filter chamber. Therefore, the quality of the produced soil mass depends on the size of the feed pressure and its degree of consolidation when the clay slurry feed is stopped.

Moriki et al. (2011b) showed that the predetermined failure criterion can be maintained if the water content of the individual clods is less than $53 \%$ and the needle penetration gradient of the soil mass is greater than $0.92 \mathrm{~N} / \mathrm{mm}$. It is determined by the following needle penetration test (Murayama et al., 2004):

diameter of the cotton needle: $0.84 \mathrm{~mm}$; penetration speed: $3 \mathrm{~mm} / \mathrm{min}$.

Figure 4 shows the results of the needle penetration testing of MDC conducted in 2007 and 2010. In this figure, both the water content and the needle penetration gradient are on the safe side (Kunita et al., 2017).

Then, Moriki et al. (2011a) proposed that the supply was stopped when the drainage rate fell below $45 \mathrm{l} / \mathrm{min}$ under the conditions of a feed pressure of $4 \mathrm{MPa}$. Table 1 shows the physical properties of the dredged sediment that they used in the experiment to produce MDC.

Moriki et al. (2011b) described the manufacturing process of MDC lumps used as extra fill on revetments as follows (see Figure 5).

(a) Preparation

(i) The high-pressure dewatering machine had some filter chambers surrounded by some filter cloths.

(ii) Gravel was removed from the diluted mud to obtain clay slurry with a water content of approximately $300 \%$ (three times of $w_{\mathrm{L}}$ ).

(iii) To this clay slurry, polyaluminium chloride (5\%) and slaked lime $(2 \%)$ were added to the weight of clay particles as an auxiliary material in the dewatering process. 
(b) Injection and dewatering

(i) During the dewatering process, the clay slurry was sent into a filter chamber for approximately $20 \mathrm{~min}$ with lowpressure pumping.

(ii) Switching to high-pressure pumping at $4 \mathrm{MPa}$, the clay slurry was fed into the chamber until the drainage rate reached $45 \mathrm{l} / \mathrm{min}$ (total filtration chamber volume $6.8 \mathrm{~m}^{3}$; volume strain rate of $0.7 \% / \mathrm{min}$ ) or less.

(c) Air blowing

(i) The centre of the chamber sending the clay slurry had a low seepage consolidation force. Thus, the low-intensity part was removed by air blowing.

(d) Removal of lumps

(i) After the preceding process, the frame was opened and the lumps were removed (see Figure 6).

\section{Characteristics of MDC lumps}

Figure 7 shows MDC lumps immediately after removal. The glove in the figure is about $250 \mathrm{~mm}$ long, which is a guide for checking the size of the soil mass. The average particle size of MDC lumps that was transported/placed temporarily after production was $31 \mathrm{~mm}$ Furthermore, the uniformity coefficient $U_{\mathrm{c}}$ which is defined by the

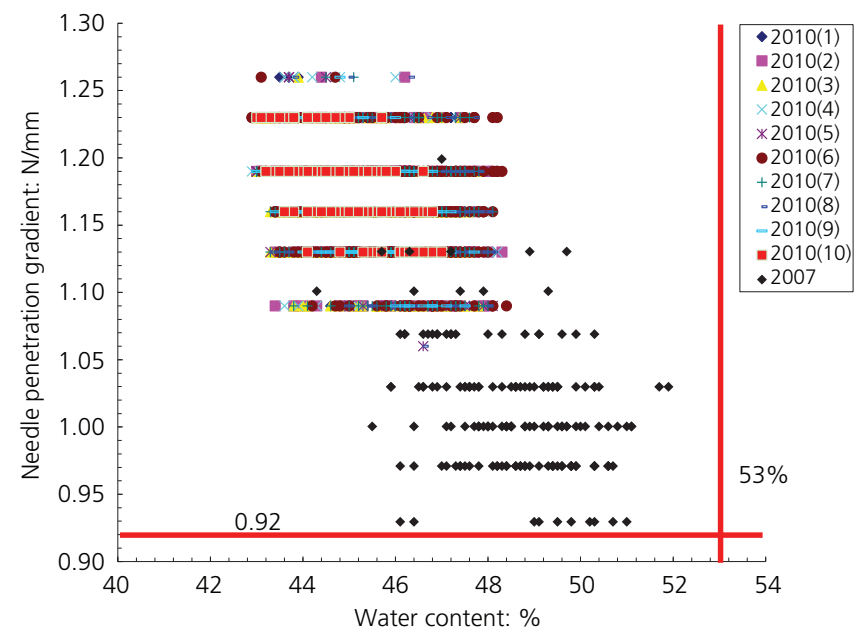

Figure 4. Water content and needle penetration gradient of MDC lumps

Table 1. Physical properties of the dredged soil used to produce MDC lumps

$\begin{array}{lc}\text { Water content: \% } & 113-214 \\ \text { Density of soil particles: } \mathrm{g} / \mathrm{cm}^{3} & 2.638-2.681 \\ \text { Liquid limit: \% } & 82-131 \\ \text { Sand fraction: \% } & 1.6-11.3\end{array}$

equation $U_{\mathrm{c}}=\mathrm{D}_{60} / \mathrm{D}_{10}$ is 18.5 . The water content of the soil mass as a quality control value when producing MDC lumps was lower than the standard value $(53 \%)$ shown by Moriki et al. (2011b). The average value was $45.3 \%$, and the maximum and the minimum values were 48.4 and $41.2 \%$, respectively. On the other hand, the needle penetration gradient of the soil mass was higher than the standard value $(0.92 \mathrm{~N} / \mathrm{mm})$, with an average value of $1.17 \mathrm{~N} / \mathrm{mm}$ and a minimum value of $1.09 \mathrm{~N} / \mathrm{mm}$.

Figure 8 shows the results of the constant pressure box shear tests performed immediately after the fabrication process at each production period. It shows failure points obtained in each experiment for MDC lumps packed to a unit weight of $14.5 \mathrm{kN} / \mathrm{m}^{3}$ with internal diameters of $200 \mathrm{~mm}$ and depths of $160 \mathrm{~mm}$ in a direct shear box under vertical stresses of 50,100 and $200 \mathrm{kPa}$. The following failure criterion, the red line in Figure 8, was set by taking the lower limit of these experimental results:

failure criterion: $c_{\mathrm{d}}=5 \mathrm{kPa}, \phi_{\mathrm{d}}=30^{\circ}$.

\section{Extra fill on existing revetments}

MDC lumps were used as materials for the extra fill and the backfill of revetments. The work was carried out using about $480000 \mathrm{~m}^{3}$ of MDC lumps, which was dewatered from $940000 \mathrm{~m}^{3}$ of dredged soil. The extra fill on revetments with MDC lumps was applied in accordance with the method of Moriki et al. (2011a). The main features are as follows:

spreading thickness: $30 \mathrm{~cm}$; unit volume weight: $16.5 \mathrm{kN} / \mathrm{m}^{3}$; slope: $1: 1.5$.

These criteria were set as the lower limit of the test results obtained in the test construction (Nakamichi et al., 2009).

The construction of the revetment over rock (see Figure 3), the level of which was $\mathrm{DL}+4.5 \mathrm{~m}$, began in 2010 . When the height of the revetment reached DL $+8.0 \mathrm{~m}$, it was levelled by heavy machinery to the same level as the existing revetment. After that, the extra fill on the revetment including number 1 and 9 points (see Figure 2) was constructed at a level of DL $+12.0 \mathrm{~m}$ in 2011. Figure 9 shows the construction status of the extra fill on revetments near the number 9 point in Figure 2 (Nakamichi et al., 2014).

\section{Durability of MDC lumps used for extra fill on revetments}

Condition of the site for 10 years

Figure 10 shows the changes in monthly rainfall and average temperature around the site from January 2010 to December 2020. There is usually a difference of around $300 \mathrm{~mm}$ in monthly rainfall between summer and winter, indicating that the area is repeatedly dry and wet. To check the deformation of extra fill on revetments, daily inspections, visual inspection (monthly) and periodic inspections by simple measurement (yearly) are conducted, but no 
Geotechnical Research

Volume 9 Issue 3
Evaluation of effective use of dredged soil as containment dikes of a disposal

pond in Japan

Nishizono, Sega, Katagiri and Watabe

High-pressure filter press method

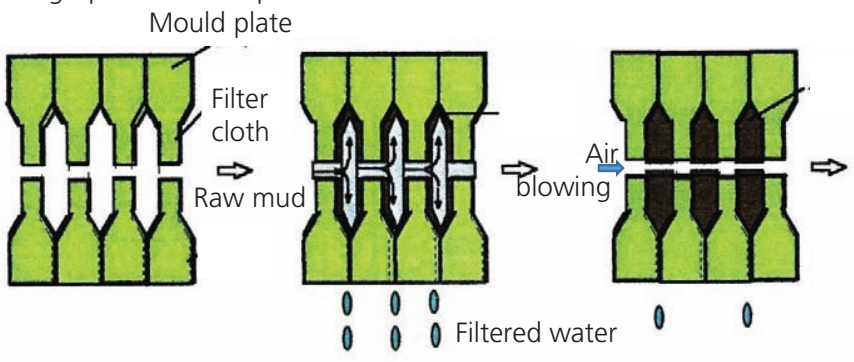

(a) Preparation

(c) Air blowing (b) Injection and dewatering

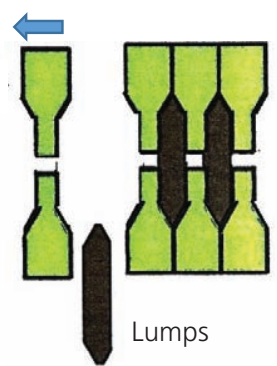

(d) Removing of lumps

Figure 5. MDC lump production process

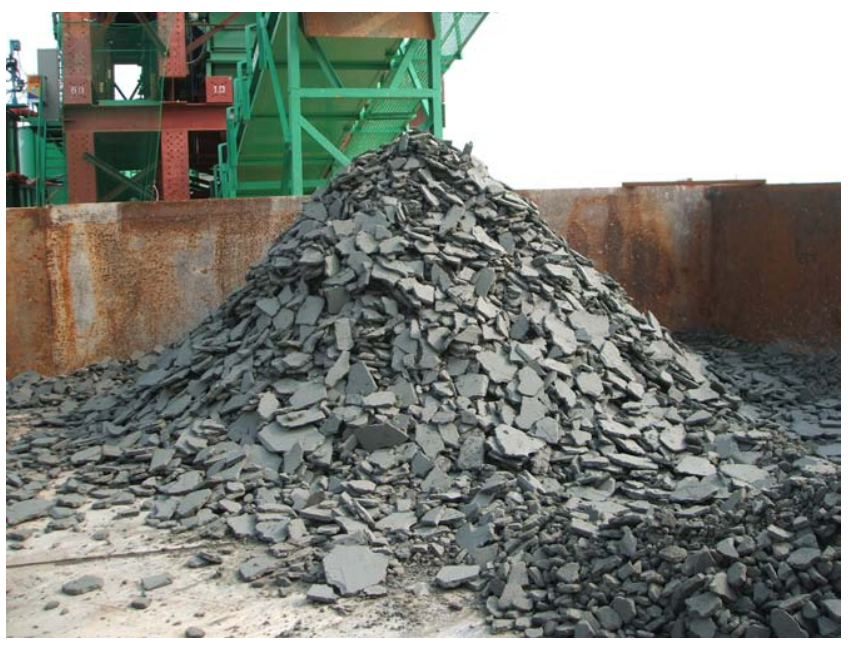

Figure 6. MDC lumps immediately after removal

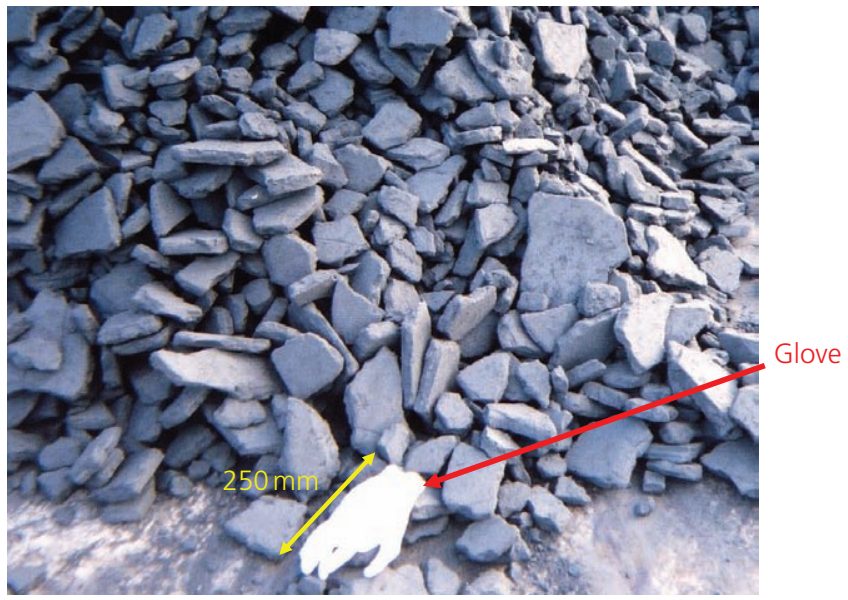

Figure 7. Dewatered soil immediately after completion

deformation such as cracks, subsidence or heaving of the slope has so far been observed.

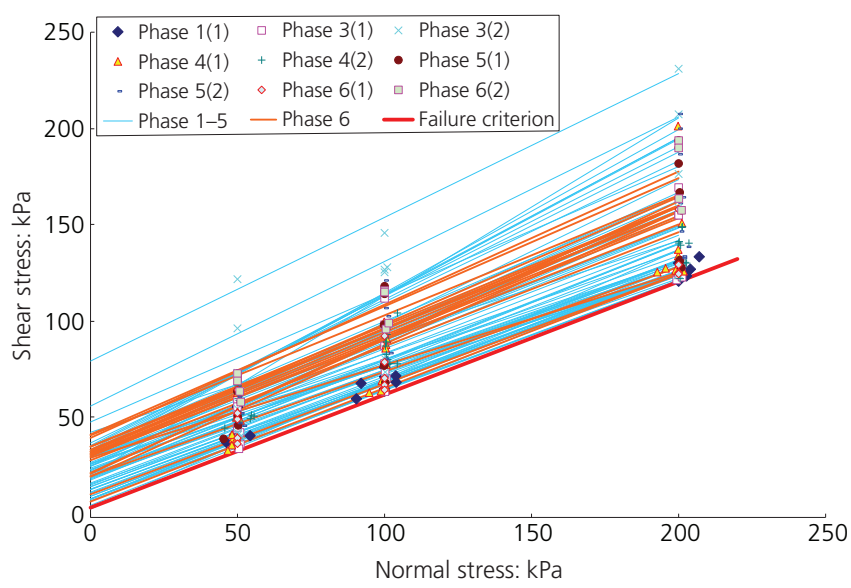

Figure 8. Fracture point and fracture line of dewatered soil immediately after completion

Chronological change in shear strength

Figure 11 shows a block sample at $0.5 \mathrm{~m}$ below the top of the extra fill on revetments in 2017. The sampling locations were number 1 near the north-east corner and number 9 near the southeast corner in Figure 2. The MDC lumps can be seen in the block, indicating that it contains uncrushed parts.

The water content and the dry density of the block sample taken every year after construction are shown in Figures 12 and 13, respectively. The water content at both sites tends to decrease in 10 years, but the dry density is almost constant.

Figure 14 shows the results of the box shear test of the block sample and the design strength $\left(c_{\mathrm{d}}=5 \mathrm{kPa}, \phi_{\mathrm{d}}=30^{\circ}\right)$ when constructing the revetments using MDC lumps by Moriki et al. (2011b). Since the shear strength at a high restraint pressure of $150 \mathrm{kPa}$ decreases relatively, the data indicate that $c_{\mathrm{d}}$ increases and $\phi_{\mathrm{d}}$ decreases. However, the effective loading pressure is about $80 \mathrm{kPa}$ because the height of the extra fill on revetment is about $4 \mathrm{~m}$, and the failure line of all data at a pressure lower than this value is above the reference fracture line. It can 
Evaluation of effective use of dredged soil as containment dikes of a disposal pond in Japan

Nishizono, Sega, Katagiri and Watabe

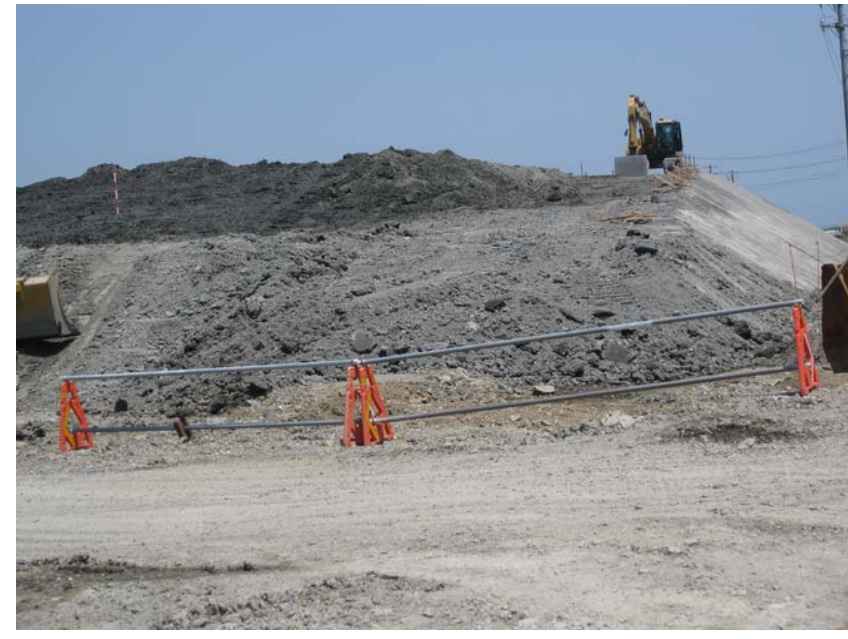

Figure 9. Extra fill on revetments using MDC lumps in 2011

be evaluated as being on the safe side. In other words, it can be confirmed that the shear strength assumed at an effective restraint pressure of $50 \mathrm{kPa}$ is higher than the failure criterion.

Figure 15 shows the change over time in the shear resistance when a vertical stress of $50 \mathrm{kPa}$ is applied. Although the strength constants varied, the shear resistances, which contribute to stability, were all higher than the designed values.

\section{Radioisotope cone penetration test}

Figure 16 shows the radioisotope cone penetration test (RI-CPT) that was conducted by a compact penetration device for the sake of safe and efficient work on high revetments. Figure 17 shows the results for the tip resistance and the sleeve friction by RI-CPT at numbers 1 and 9 . The

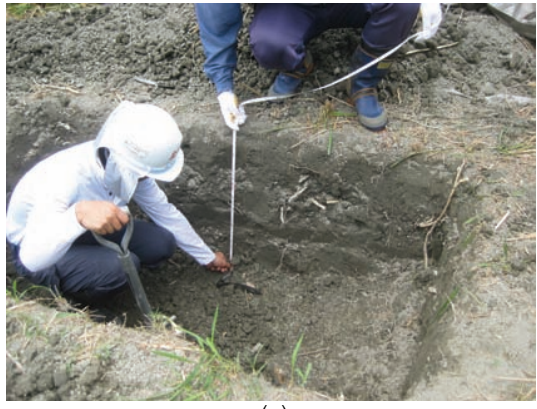

(a)

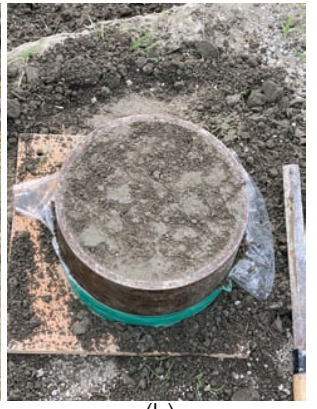

(b)
Figure 11. Block sample of the extra fill in 2011: (a) $0.5 \mathrm{~m}$ below of the top; (b) MDC lumps in the block

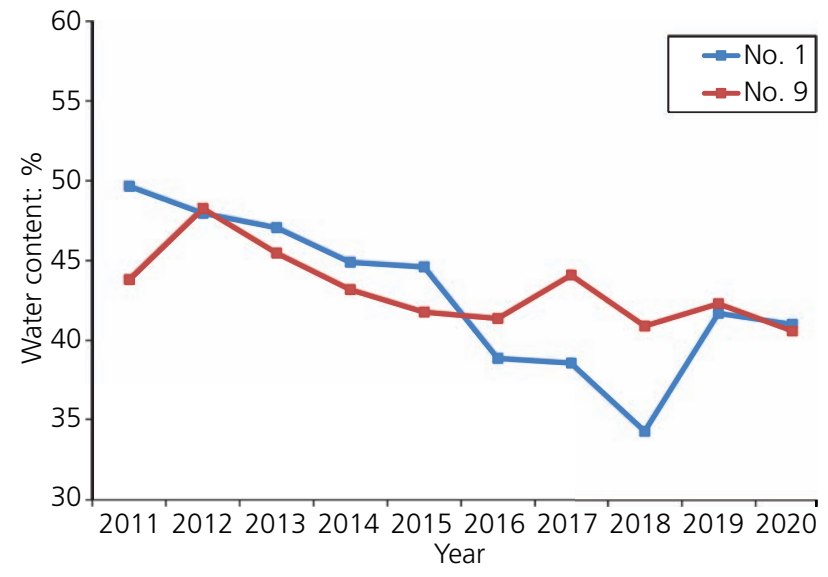

Figure 12. Change in the water content of the block sample

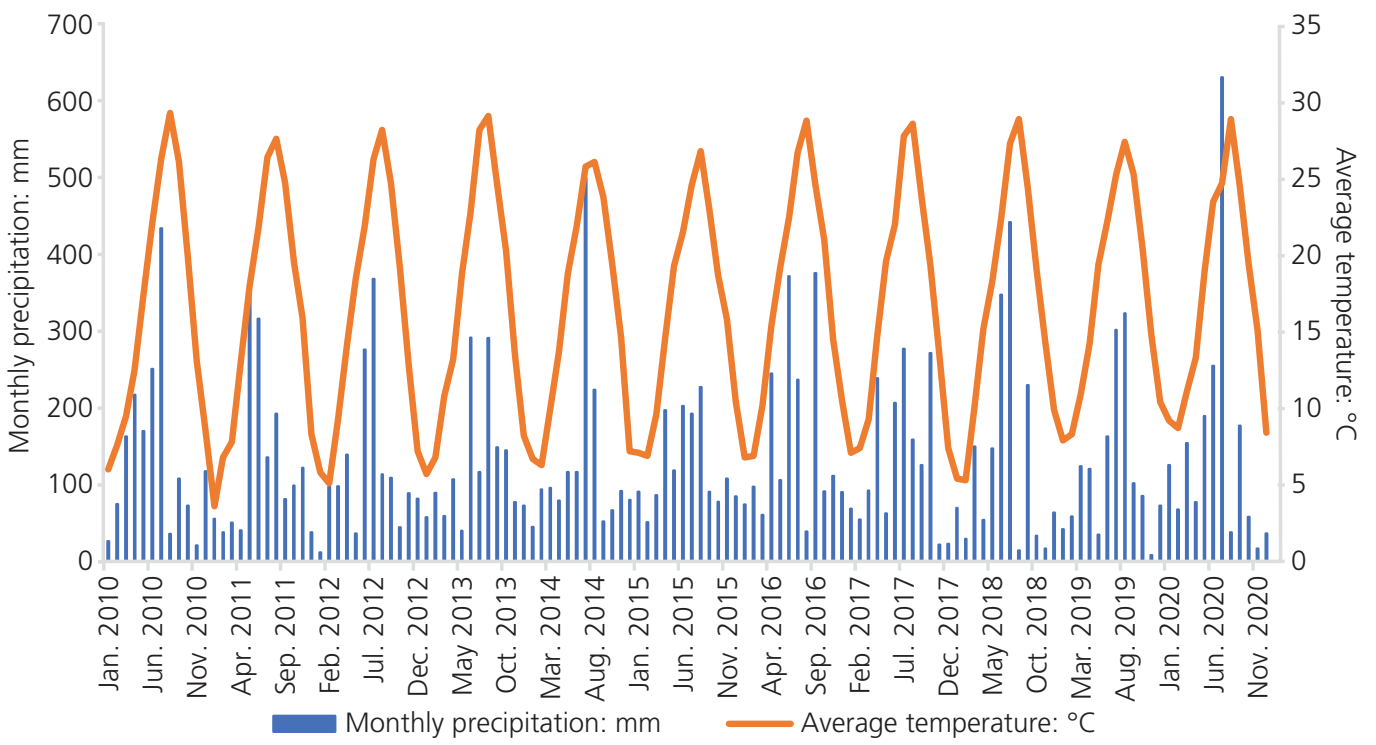

Figure 10. Changes in monthly rainfall and average temperature at the Kitakyushu airport near the site 
Evaluation of effective use of dredged soil as containment dikes of a disposal

pond in Japan

Nishizono, Sega, Katagiri and Watabe

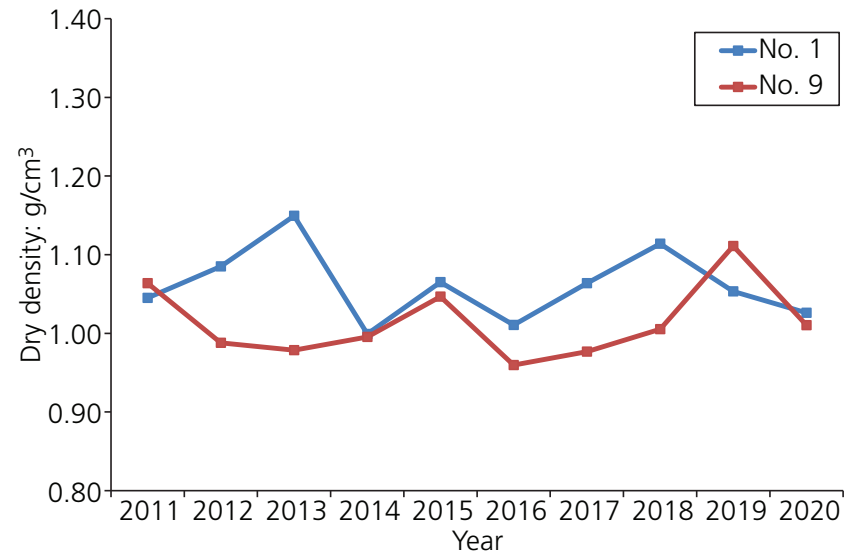

Figure 13. Change in the dry density of the block sample

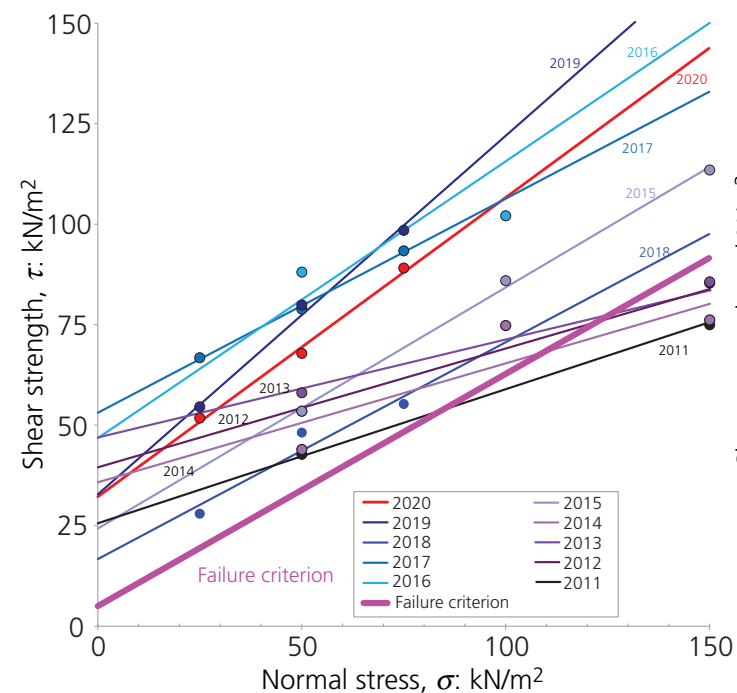

(a) values at each location are almost the same as those 10 years ago. Number 1 shows almost no change in the depth direction, while number 9 shows a large increase around DL $+8 \mathrm{~m}$ between the extra fill and backfill. This is probably because heavy machinery frequently passed at the level of $\mathrm{DL}+8 \mathrm{~m}$ and the ground was compacted.

Figure 18 extracts the four graphs shown in Figure 17 - that is, the 2011 and 2020 data for numbers 1 and 9 . From this figure, it can be seen that the data for 2011 and 2020 did not change significantly in the depth direction for both the tip resistance and the sleeve friction.

Figure 19(a) shows the moisture density $\left(\rho_{\mathrm{m}}\right)$ measured by RI-CPT in number 1 . It estimates the distribution of dry density $\left(\rho_{\mathrm{d}}\right)$, wet density $\left(\rho_{\mathrm{t}}\right)$, water content $(w)$ and saturation $\left(S_{\mathrm{r}}\right)$ for the decade from 2011. The water content distribution is almost the same as that 10 years ago, and it shows almost no change in the depth direction.

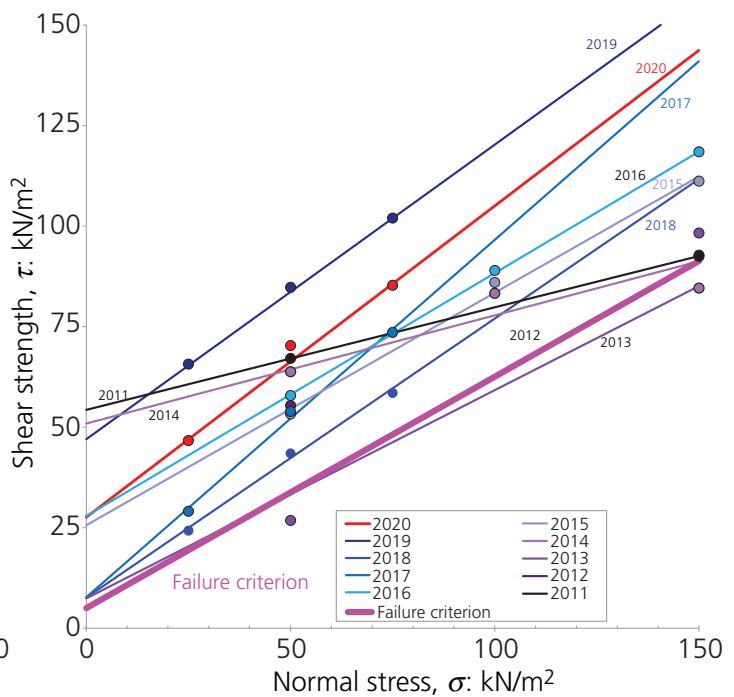

(b)

Figure 14. Change in the failure strength with time and the failure criterion of the block sample: (a) results from number 1 ; (b) results from number 9

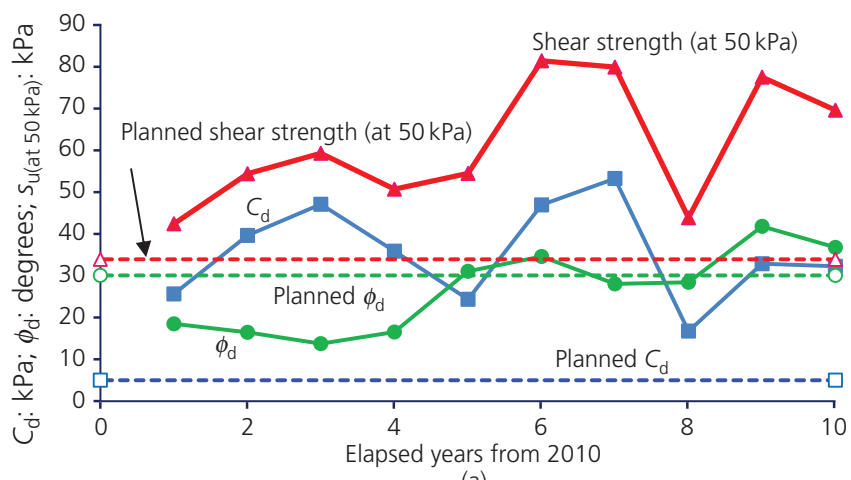

(a)

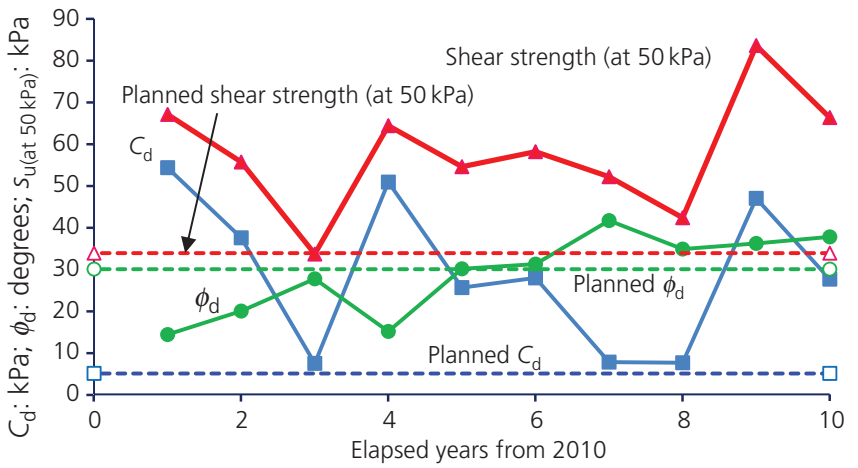

(b)

Figure 15. Changes in the strength constant and shear strength at $50 \mathrm{kPa}$ with a box shear test: (a) results from number 1 ; (b) results from number 9 
Evaluation of effective use of dredged soil as containment dikes of a disposal pond in Japan

Nishizono, Sega, Katagiri and Watabe
Figure 19(b) shows the results of the water content by RI-CPT in number 9 . The value is almost the same as that 10 years ago, but it shows a decrease around DL $+8 \mathrm{~m}$ between the extra fill and the backfill. The circles under DL $+12.0 \mathrm{~m}$ in the figure represent the data of block samples. The water content values correspond roughly to the actual measurements of Figure 12.

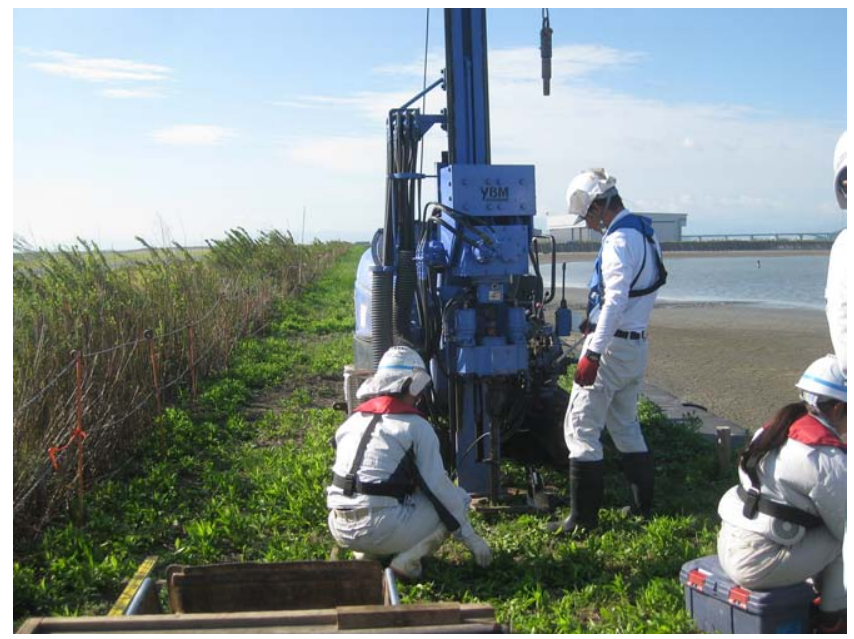

Figure 16. Conduction of RI-CPT

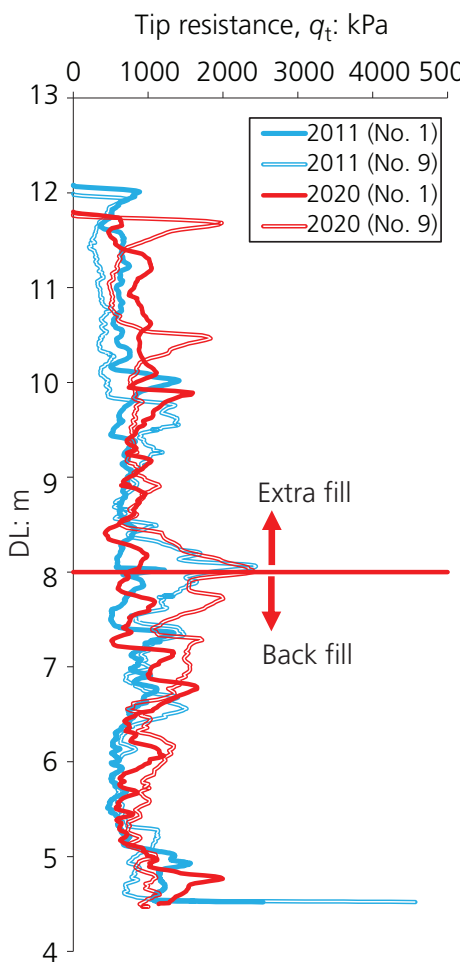

(a)
Sleeve friction, $f_{s}: \mathrm{kPa}$

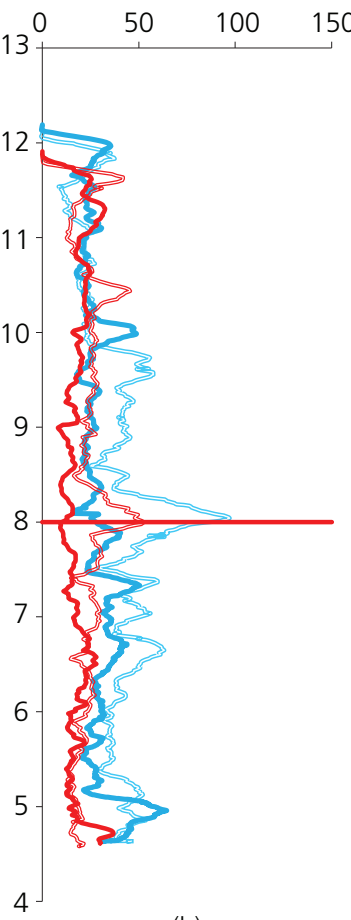

(b)

Figure 18. Comparison of 2011 and 2020 for $(a) q_{\mathrm{t}}$ and (b) $f_{\mathrm{s}}$

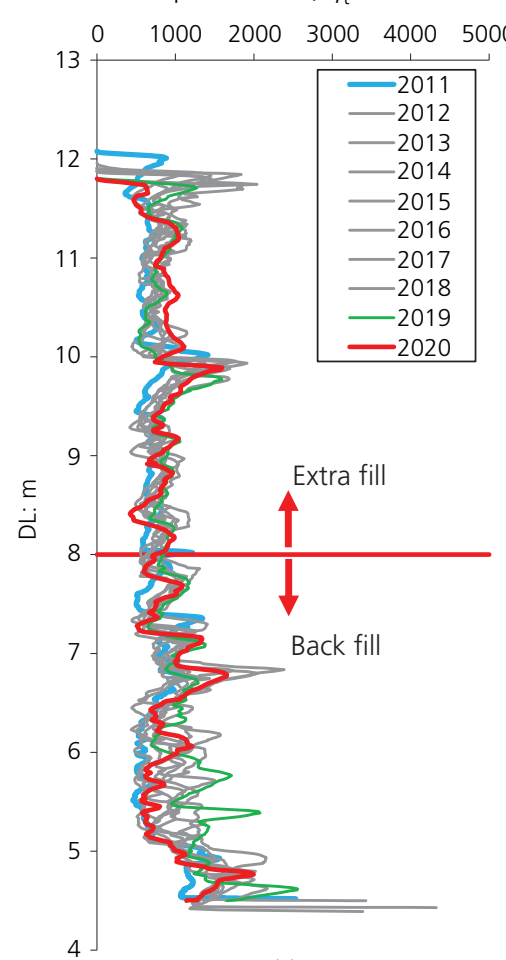

(a)
Sleeve friction, $f_{\mathrm{s}}: \mathrm{kPa}$

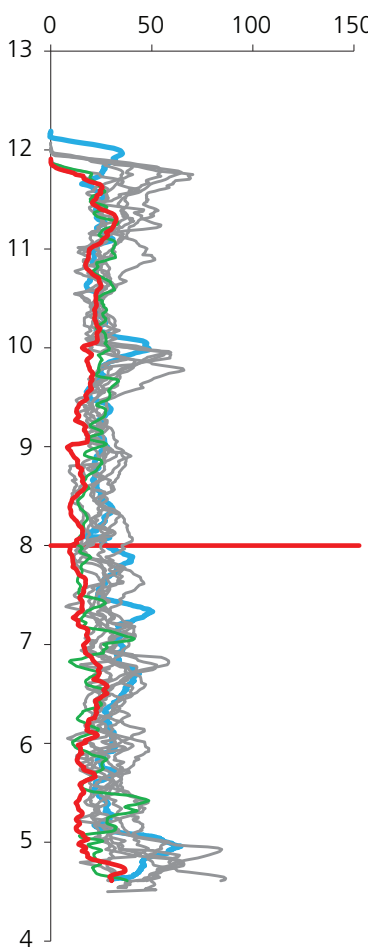

Tip resistance, $q_{\mathrm{t}}: \mathrm{kPa}$

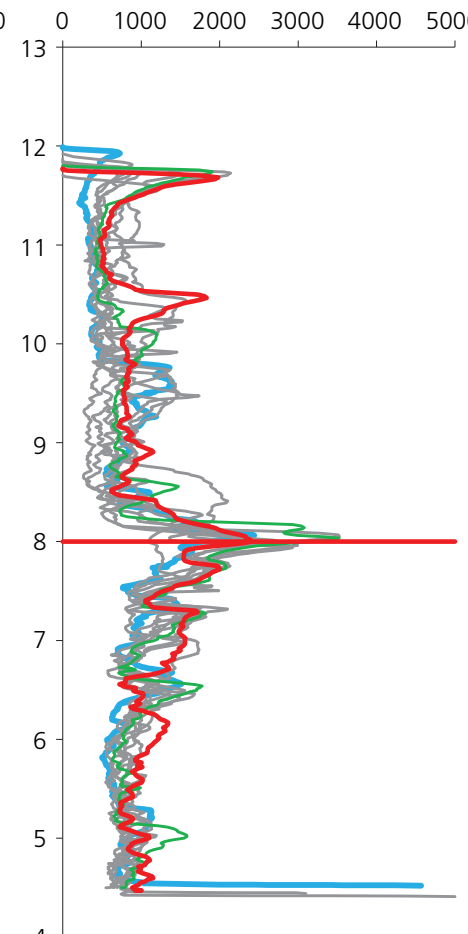

(c)

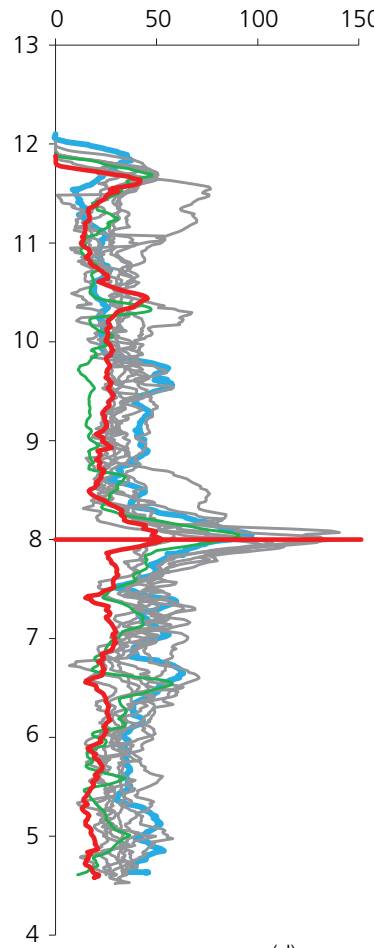

(d)

Figure 17. Tip resistance $\left(q_{t}\right)$ and sleeve friction $\left(f_{s}\right)$ by RI-CPT: (a) $q_{t}$ for number $1,(b) f_{s}$ for number $1,(c) q_{t}$ for number 9 , (d) $f_{s}$ for number 9 
Geotechnical Research

Volume 9 issue 3
Evaluation of effective use of dredged soil as containment dikes of a disposal

pond in Japan

Nishizono, Sega, Katagiri and Watabe

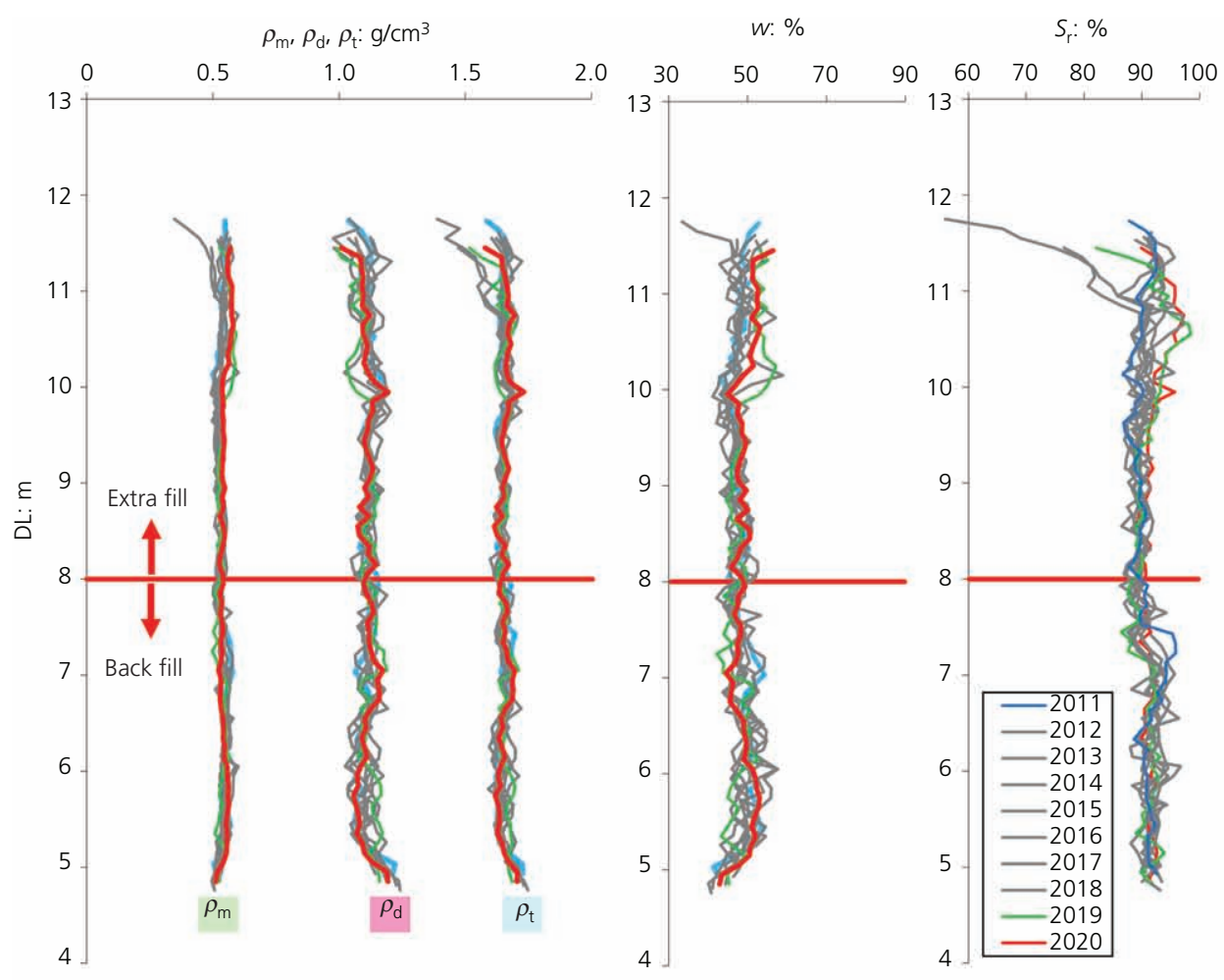

(a)

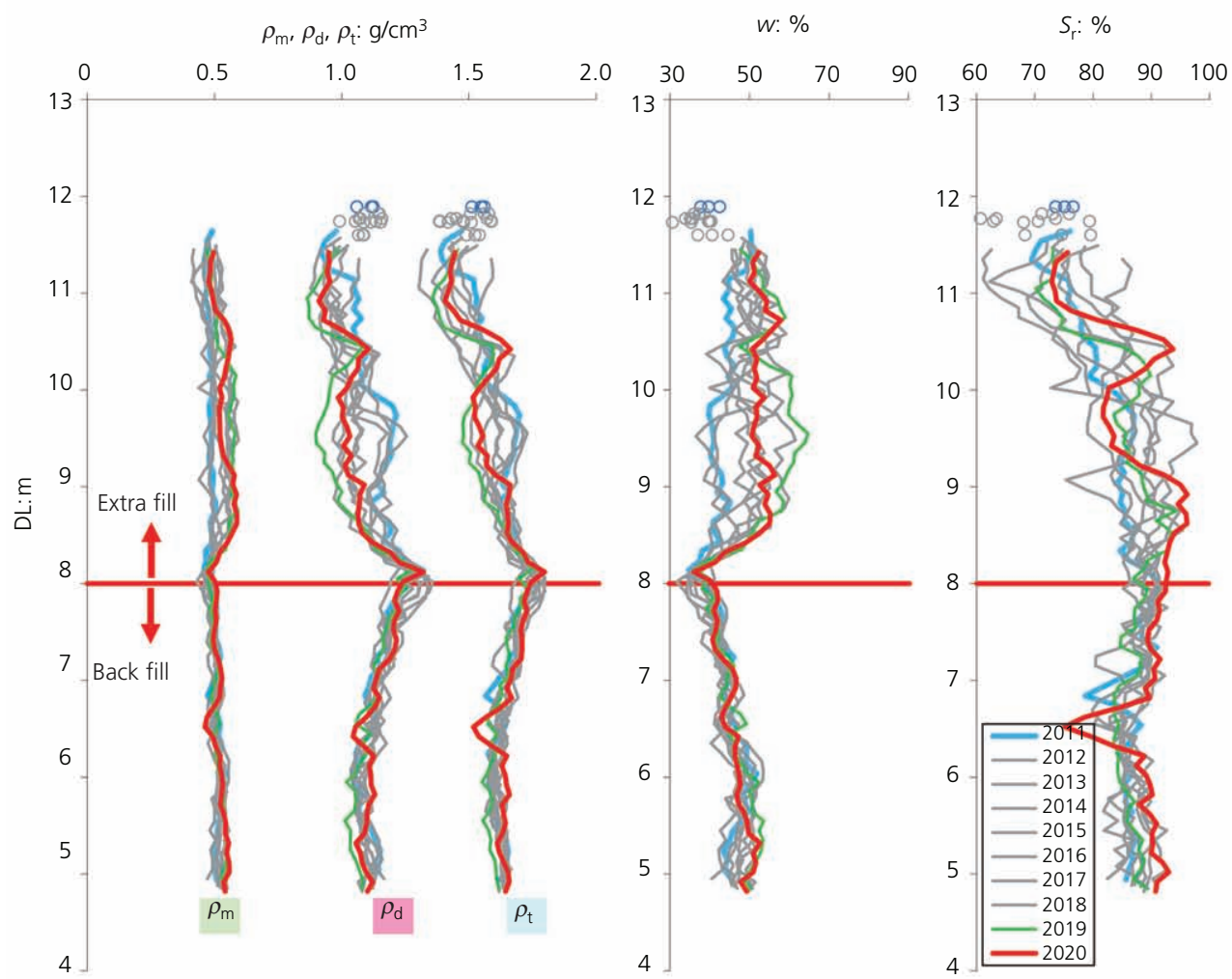

(b)

Figure 19. Distribution of physical properties estimated by RI-CPT in (a) number 1 and (b) number 9 


\section{Surface wave velocity $\left(v_{s}\right)$}

It is impossible to conduct the box shear test and RI-CPT in all the S-3 areas in the Shinmoji-Oki disposal pond, because the total length of the revetment is about $4 \mathrm{~km}$. Thus, the shear wave velocity was measured by multi-channel analysis of surface waves (MASW), in which it is possible to determine quickly the hardness of the ground.
The paper by Kunita et al. (2018) shows the results of the MASW conducted at numbers 1 and 9 in 2020 (see Figure 20). The shear wave velocity of the backfill, elevation under $8 \mathrm{~m}$, is more than $150 \mathrm{~m} / \mathrm{s}$, which is almost the same value as that of sand. The closer it is to the ground surface, the smaller the velocity of the extra fill becomes, but the lower limit of $80 \mathrm{~m} / \mathrm{s}$ is still satisfied.
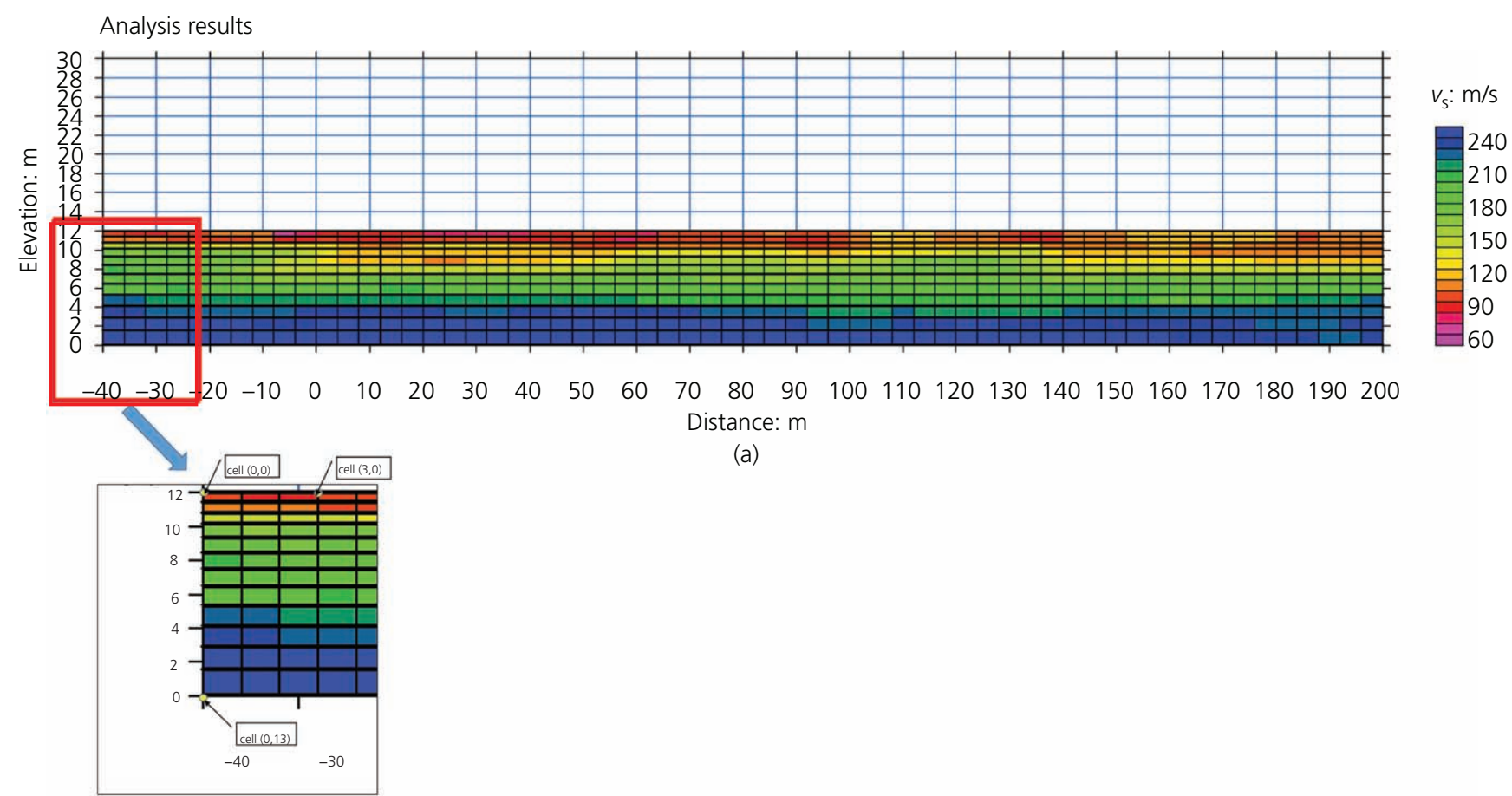

(a)

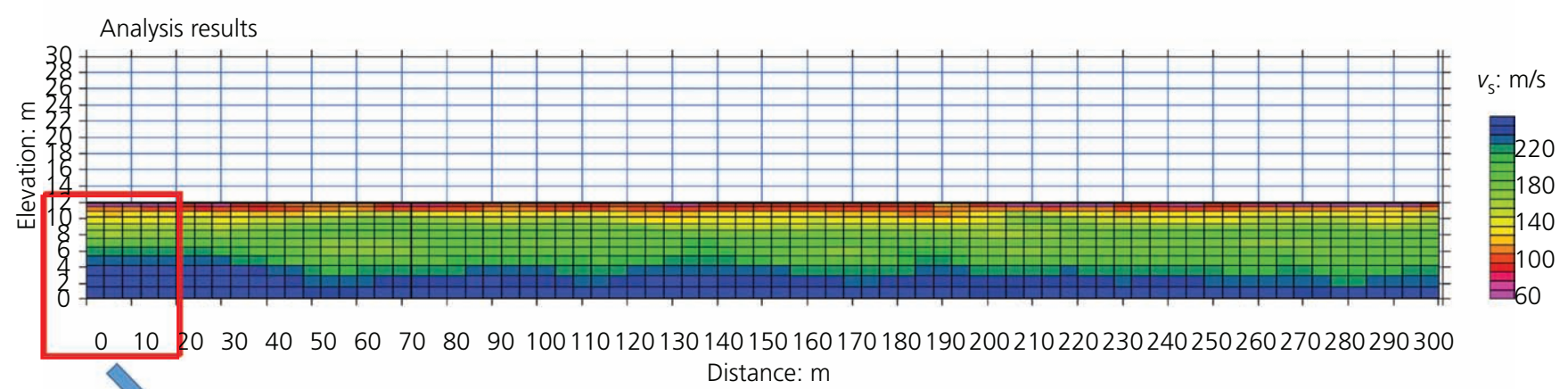

(b)

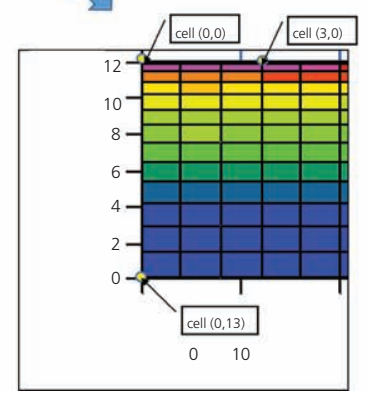

Figure 20. Surface wave velocities $\left(v_{s}\right)$ in (a) number 1 and (b) number 9 
Evaluation of effective use of dredged soil as containment dikes of a disposal pond in Japan

Nishizono, Sega, Katagiri and Watabe

\section{Durability of MDC lumps used for revetments}

\section{Annual changes}

The box shear tests have been conducted by using the block sample from the two areas, numbers 1 and 9, at a depth of $0.5 \mathrm{~m}$ from the surface for 10 years since the revetment was constructed. Furthermore, RI-CPT has been conducted annually to characterise the depth direction. As a result of these tests and investigations, the water content at $0.5 \mathrm{~m}$ from the surface has gradually decreased and the dry density is almost the same as the value at the beginning of construction. Although the strength varied depending on the year in which the test was conducted, it was confirmed that the strength was above the design value.

\section{Change in depth directions}

At number 1, there is no significant change in depth direction, but at number 9 , the values of the tip resistance $\left(q_{\mathrm{t}}\right)$ and sleeve friction $\left(f_{\mathrm{s}}\right)$ are extremely large, and the value of the water content ratio $(w)$ is extremely small around $\mathrm{DL}+8.0 \mathrm{~m}$. This can be attributed to the fact that the ground in the vicinity of the boundary between the extra fill and the backfill in number 9 was sufficiently compacted during the levelling by heavy machinery at the construction. This is evident from the difference in shear wave velocity $\left(v_{\mathrm{s}}\right)$ between the extra fill and the backfill.

\section{Conclusions}

The characteristics of MDC lumps for 10 years after construction were ascertained by the box shear test on the block samples, the tip resistance $\left(q_{\mathrm{t}}\right)$ by RI-CPT and the shear wave velocity $\left(v_{\mathrm{s}}\right)$. Some of the strength constants obtained from the box shear test of the block samples are lower than the values at the design stage, but it is confirmed that the shear strength in the effective loading range of the extra fill on the revetment is higher than the failure criterion. In other words, the stability of the revetment raised by MDC lumps has been satisfied.

\section{REFERENCES}

Katagiri M and Terashi M (2005) Volume reduction of clay to extend the life of disposal pond. Proceedings of the 2nd Sino-Japanese Symposium on Geotechnical Engineering, Shanghai, China, pp. 738-745.

Kunita A, Higuchi A, Nakashima H et al. (2017) Construction of additional embankment by using dewatered dredged clay. Kisoko 45(9): 61-65 (in Japanese).

Kunita A, Higuchi A, Nakashima H et al. (2018) Geotechnical characteristics embankment mounted with dewatered clay lumps. Journal of Japan Society of Civil Engineers, Ser. B3 (Ocean Engineering) 74(2): I_892-I_897, https://doi.org/10.2208/jscejoe.74. I 892 (in Japanese).

Moriki A, Katagiri M and Terashi M (2011a) Mechanical properties of dewatered dredged clay lumps. Proceedings of the 14th Asian Regional Conference on Soil Mechanics and Geotechnical Engineering, Hong Kong, China, vol. 2, pp. 1411-1416, DVD-ROM.

Moriki A, Yamamoto S and Katagiri M (2011b) Design method of additional embankment using dredged marine clay lumps. Tsuchi-to-Kiso 59(7): 22-25, https://doi.org/10.1680/jgere.21.00031 (in Japanese).

Murayama I, Kajiwara K, Takeda H et al. (2004) Mechanical behavior of a filter-pressed clay lump and their interactions. Proceedings of the 49th JGS Symposium, Tokyo, Japan, pp. 91-98 (in Japanese).

Nakamichi M, Yano Y, Migita $\mathrm{H}$ et al. (2008) Trial construction of revetment backfill using dewatered clay lumps. Proceedings of the Eighth ISOPE Pacific/Asia Offshore Mechanics Symposium (PACOMS 2008), Bangkok, Thailand, pp. 200-205.

Nakamichi M, Yano Y, Migita $\mathrm{H}$ et al. (2009) Characteristics of embankment made with dewatered clay lumps and a proposal of their design method. In Proceedings of the 8th Symposium on Environmental Geotechnical Engineering, Tokyo, Japan, pp. 69-76 (in Japanese).

Nakamichi M, Kawano M, Umeyama T et al. (2014) Capacity increment project of Shin-Mojioki disposal pond. Proceedings of the 59th JGS Symposium, Nagano, Japan, pp. 667-674 (in Japanese).

\section{How can you contribute?}

To discuss this paper, please submit up to 500 words to the editor at journals@ice.org.uk. Your contribution will be forwarded to the author(s) for a reply and, if considered appropriate by the editorial board, it will be published as a discussion in a future issue of the journal. 